\title{
Content analysis of the South African MMed mini-dissertation
}

\author{
E S Grossman, PhD \\ East London and Port Elizabeth Health Resource Centres, Faculty of Health Sciences, Walter Sisulu University, Eastern Cape Province, South Africa
}

Corresponding author: E S Grossman (grossmane@gmail.com)

\begin{abstract}
Background. There is no baseline information on the South African (SA) MMed mini-dissertation, which became a compulsory (and controversial) research component for specialist registration in 2011.

Objective. To obtain evidence-based information regarding the current composition of the research output of the MMed mini-dissertation.

Methods. SA MMed mini-dissertations $(N=307)$ were downloaded from electronic theses and dissertation websites and 8 university repositories that provide specialist training. Fourteen variables were noted for each mini-dissertation, the data were entered into an Excel (2016) (Microsoft, USA) spreadsheet and analysed using descriptive statistics.

Results. The 307 mini-dissertations, representing 24 of the Colleges of Medicine of SA, were submitted from 1996 to 2018, mainly in monograph format (76\%) and almost equally divided between prospective and retrospective studies. Observational studies predominated, with meta-analyses, systematic reviews and randomised controlled trials comprising $5 \%$ of the sample. Although quantitative investigations dominated (82\%), just less than half of these used statistics to test variables. Confirmed ethical compliance improved from $41 \%$ in pre-2011 dissertations to $83 \%$ for dissertations submitted during 2015 - 2018.

Conclusions. This study provides descriptive data on the SA MMed mini-dissertation. Comparisons indicate that the MMed research component compares favourably with the content and research approach of similar international specialist trainee research outputs.
\end{abstract}

Afr J Health Professions Educ 2020;12(2):56-61. https://doi.org/10.7196/AJHPE.2020.v12i2.1227

The decision by the Health Professionals Council of South Africa (HPCSA) to regulate a research component in the form of a mini-dissertation (Master of Medicine (MMed)) for specialist registration, was accorded a mixed reception when implemented in 2011. While most South African (SA) surgical registrars consider research an important component of their careers, ${ }^{[1]}$ some view the research requirement as an imposition on their clinical training time and were sufficiently incensed to legally challenge the decree ${ }^{[2]}$ There also appears to be divergent understandings of the purpose of the MMed among the SA specialist trainer cohort. ${ }^{[3-5]}$ The HPCSA ruling, introduced to solve existing problems of variations between training centres, correspondingly addressed a number of researchrelated and clinically meaningful concerns. Anaesthetists in the USA warn that the status of their profession is at risk of becoming a trade union if research training is not enhanced. ${ }^{[6]}$ European family physicians fail to see the direct association between research and clinical reality, limiting their ability to practise evidence-based medicine, ${ }^{[7]}$ while psychiatrists at the University of Maryland, Baltimore, USA, highlight the serious shortage of physician researchers, which impacts the profession at large ${ }^{[8]}$ It is important, at this point, to understand that SA is not alone in incorporating a research component into the trainee specialist programme. In other parts of the world, similar steps have been taken to integrate research training in specialist curricula, thereby preparing trainees for future challenges. It is unsurprising that they have also encountered comparable sticking points and wrestle with similar conflicting stances. ${ }^{[7,9-15]}$

Given the robust discussion about the appropriateness of the MMed in specialty training, ${ }^{[2-5,16]}$ it is surprising that, 9 years after the implementation of the HPCSA decree, the extent and nature of the SA MMed remain unstudied. It therefore seems an appropriate time to take stock of the MMed by presenting evidence-based information about the current composition of the research output. Such information will assist in identifying strengths and deficiencies in the research programme and provide facts for monitoring, reviewing and decision-making on policy, and programme and project performance of trainee specialist research. Should future changes be implemented, evidence such as that provided here can serve as a reference for determining change. Finally, details on current MMed mini-dissertations can assist candidates to improve the structure of their dissertations and offer a glimpse of the quality and relevance of institutional research. Therefore, the following descriptive study was undertaken to provide basic information on qualifying SA MMed mini-dissertations sampled between 1996 and 2018.

\section{Methods}

This was a record review of SA MMed mini-dissertations downloaded from local (www.netd.ac.za) and global (www.ndltd.org) electronic theses and dissertation websites. University library repositories of the 8 universities that train registrars were similarly searched until each inquiry revealed proportionally more spurious targets than strikes, whereafter the search was discontinued. Acceptable evidence of MMed research competency has many permutations. Cochrane reviews ${ }^{[17]}$ and reprints of a single published paper in pdf format ${ }^{[18]}$ were encountered, apart from the typical mini-dissertation in monograph or publication-ready format. To obtain a uniform study sample that could provide all the desired data, two inclusion criteria were applied:

- The output had to be identified as an MMed and/or include the Colleges of Medicine of SA (CMSA) specialty discipline.

- The MMed had to be in either monograph or publication-ready format. 
Excluded were single pdf journal papers, Cochrane reviews and any other MMed qualifiers that did not fulfil the inclusion criteria. Each retrieved MMed was identified for author, title, year of submission, ethical clearance, university and whether the submission was in monograph or publicationready format. The appropriate college in the CMSA (www.cmsa.co.za), indicating the clinical discipline under which the candidate was registered, was noted, as well as study type, design and data analysis. In each case the research approach was ranked as per the hierarchy of evidence and clinical decision-making. Finally, the number of study samples or participants, references and mini-dissertation page numbers were recorded. The data were entered into an Excel (2016) (Microsoft, USA) spreadsheet and analysed using descriptive statistics (mean, standard deviation, range and median).

\section{Ethical approval}

Ethical approval was obtained from the Walter Sisulu University, Faculty of Health Sciences, Postgraduate Education, Training, Research and Ethics Unit: Human Research Committee clearance certificate (ref. no. 032/2019).

\section{Results}

A total of 307 MMed mini-dissertations comprised the study sample.

\section{General}

\section{University}

All 8 universities offering specialist training were represented (Table 1). The University of Pretoria (UP) is under-recorded because MMed research outputs are permitted as a single pdf journal publication, which fell outside the selection criteria of the study.

\section{Clinical discipline}

There were 24 Colleges in the sample (Table 1).

\section{Submission years}

Year of submission ranged from 1996 to 2018, with peak numbers occurring in 2014. MMed submission started rising in 2010 in anticipation of the HPCSA ruling (Fig. 1).

\section{MMed layout}

Both MMed formats selected for this study had layout variations. The typical monograph followed the broad outline of front matter, introduction, methods, results, discussion and references. Some MMeds included an Afrikaans translation of the English abstract (a university norm) and in one instance the entire monograph was in Afrikaans. ${ }^{[19]}$ Publication-ready format MMeds are generally structured to include the original research proposal, a structured literature review and a publication-ready manuscript or published article for a named, peer-reviewed journal. The 'Instructions to authors' of the journal are incorporated and co-author contribution is stated. Most publication-ready MMeds adhered to the abovementioned provisos. In monograph and publication-ready formats, one or more of the following were encountered: approval of a departure from the original protocol; ethical approval document; extensions to the original ethical approval; plagiarism report; copy of the university mini-dissertation guidelines; annual student progress report; confirmation of word count of each section; outline of referencing style used; and, finally, verification
Table 1. University and college affiliations for MMed minidissertations, $N=307$

\begin{tabular}{|c|c|}
\hline Affiliations & $n(\%)$ \\
\hline \multicolumn{2}{|l|}{ University } \\
\hline UCT & $87(28)$ \\
\hline Wits & $69(22)$ \\
\hline SU & $45(15)$ \\
\hline UKZN & $44(14)$ \\
\hline SMU $^{*}$ & $30(10)$ \\
\hline UP & $14(5)$ \\
\hline UFS & $11(4)$ \\
\hline WSU & $7(2)$ \\
\hline \multicolumn{2}{|l|}{ College $^{\dagger}$} \\
\hline COG & $58(19)$ \\
\hline СРНM & $36(12)$ \\
\hline CFP & $34(11)$ \\
\hline $\mathrm{CA}$ & $29(9)$ \\
\hline CPaed & $23(7)$ \\
\hline CS & $17(5)$ \\
\hline $\mathrm{CP}$ & $16(5)$ \\
\hline COrth & $15(5)$ \\
\hline CRO & $14(5)$ \\
\hline CPath & $11(4)$ \\
\hline CPsych & $11(4)$ \\
\hline COphth & $7(2)$ \\
\hline COrl & $7(2)$ \\
\hline CNeurosurg & $6(2)$ \\
\hline CPlast & $4(1)$ \\
\hline CForPath & $3(1)$ \\
\hline CEM & $3(1)$ \\
\hline CDerm & $2(1)$ \\
\hline CNeurol & $2(1)$ \\
\hline CNP & $2(1)$ \\
\hline CPS & $2(1)$ \\
\hline CMG & $1(0.3)$ \\
\hline $\mathrm{CR}$ & $1(0.3)$ \\
\hline $\mathrm{CU}$ & $1(0.3)$ \\
\hline \multicolumn{2}{|c|}{ 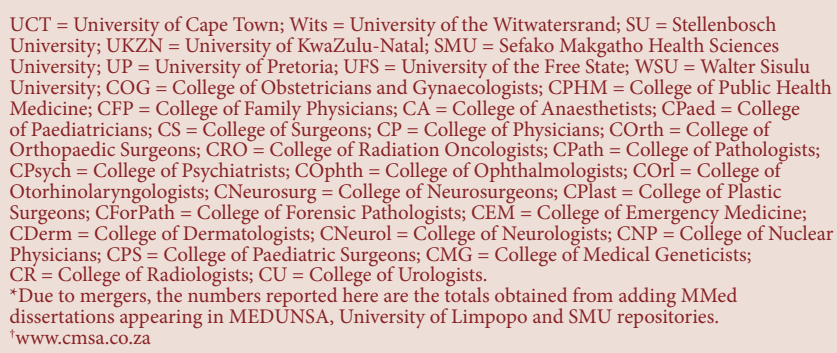 } \\
\hline
\end{tabular}

by the statistician of statistical analysis undertaken. Omissions were the absence of traditional front matter, table of contents, list of figures or tables, abstract and appendix.

\section{Descriptive findings \\ MMed format}

The majority of MMeds were in monograph format $(n=236)$, with 71 in publication format (Table 2). The first publication-ready MMed sampled 


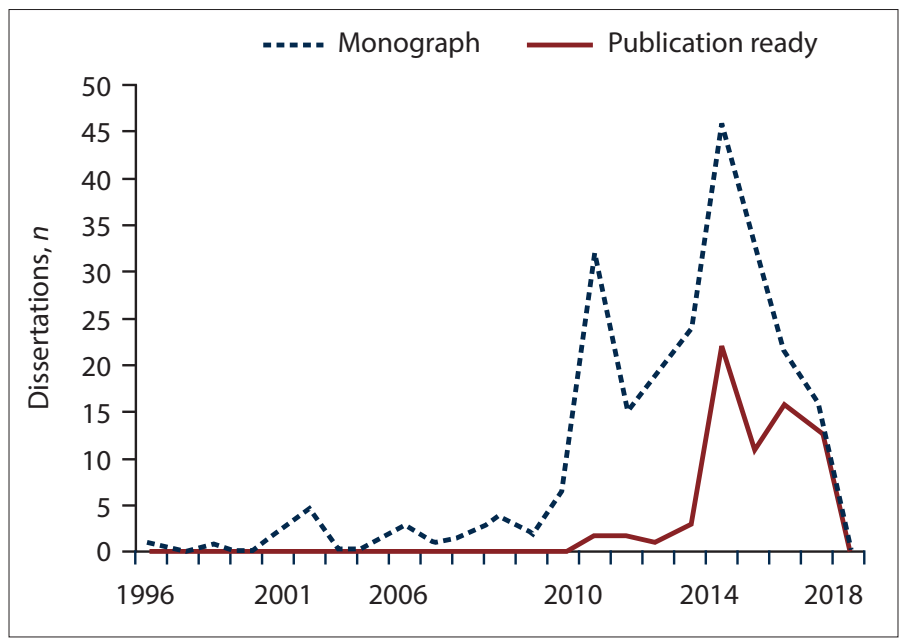

Fig. 1. Graph of submission year and mini-dissertation format for the $307 \mathrm{MMed}$ mini-dissertations sampled. The decrease in numbers from 2015 onwards is probably due to the time lag between mini-dissertation completion and website uploading. The first publication-ready MMed was in 2010; this has become an increasingly popular submission format.

was in 2010; from 2014 onwards, this format formed around half of the submitted mini-dissertations for each year (Fig. 1).

\section{Prospective/retrospective studies}

Investigations were almost equally divided between prospective $(n=158)$ and retrospective ( $n=149)$ studies (Table 2).

\section{Investigation type}

The vast majority of studies were quantitative $(n=254)$, with 41 MMed students undertaking qualitative research and 12 using a mixed methods approach (Table 2).

\section{Quantitative data analysis}

Just fewer than half $(n=122)$ of the 254 quantitative studies used statistics to compare variables or test hypotheses, while the other 132 used simple descriptive statistics (Table 2).

\section{Research approach}

Observational studies such as case studies and reports predominated (Table 2). Research approaches that provide the best evidence-based information, such as meta-analyses, systematic reviews and randomised controlled trials, comprised $\sim 5 \%$ of the sample. When broken down by prospective and retrospective approaches (Table 3), surveys (28.9\%) and cohort studies $(20.1 \%)$ comprised half of prospective approaches. Case studies and reports (70.9\%) dominated retrospective research investigations. The category 'Management' of 25 mini-dissertations, grouped a diverse collection of studies, which included a hospital quality-improvement cycle, ${ }^{[20]}$ the appeals process against the Mental Health Care Act ${ }^{[21]}$ and the impact of family physicians in a district health system. ${ }^{[2]}$

\section{Ethical compliance}

A total of 220 MMeds had a confirmed ethical clearance or waiver with dated evidence provided. Of the remaining mini-dissertations, 68

\begin{tabular}{ll} 
Table 2. Content of MMed mini-dissertations, $N=307$ \\
\hline Mini-dissertations & $n(\%)$ \\
\hline Format & $236(77)$ \\
$\quad$ Monograph & $71(23)$ \\
$\quad$ Publication ready & \\
Studies & $159(52)$ \\
$\quad$ Prospective & $148(48)$ \\
$\quad$ Retrospective & \\
Research & $254(83)$ \\
Quantitative & $41(13)$ \\
Qualitative & $12(4)$ \\
Mixed methods & \\
Data analysis for quantitative studies, $n=254$ & $132(52)$ \\
Descriptive & $122(48)$ \\
Statistical testing of variables & \\
Research approach ranked as hierarchy of & \\
evidence & $1(0.3)$ \\
Meta-analysis & $3(1)$ \\
Systematic review & $12(4)$ \\
Randomised controlled trial & $49(16)$ \\
Cohort & $17(5.7)$ \\
Case control & $121(39)$ \\
Case study and report & $17(5.7)$ \\
Narrative & \\
Research categories outside hierarchy of evidence & \\
Survey & $46(15)$ \\
Management & $25(8.1)$ \\
Experiment/laboratory & $16(5.2)$ \\
Pages & Mean; median (range) \\
Sample, $n=307$ & $76 ; 67(12-260)$ \\
Monograph, $n=235$ & $77 ; 67(12-260)$ \\
Publication ready, $n=72$ & $73 ; 67(17-164)$ \\
References & $51 ; 40(6-229)$ \\
Sample & \\
Range, $n=307$ & 13 \\
No size stated & 28563 \\
& \\
\hline
\end{tabular}

Table 3. Research approach to prospective and retrospective studies for MMed mini-dissertations, $N=307$

\begin{tabular}{lll}
\hline Approach & $\begin{array}{l}\text { Prospective } \\
(\boldsymbol{n}=\mathbf{1 5 9}), \%\end{array}$ & $\begin{array}{l}\text { Retrospective } \\
(\boldsymbol{n}=\mathbf{1 4 8}), \%\end{array}$ \\
\hline Meta-analysis & 0.0 & 0.7 \\
Systematic review & 0.0 & 2.0 \\
Randomised controlled trial & 7.6 & 0.0 \\
Cohort & 20.1 & 11.5 \\
Case control & 6.3 & 4.7 \\
Case study and report & 10.1 & 70.9 \\
Narrative & 9.4 & 1.4 \\
Survey & 28.9 & 0.0 \\
Management & 10.7 & 5.4 \\
Experimental/laboratory & 6.9 & 3.4
\end{tabular}

mentioned that ethical clearance was obtained, but lacked confirmation; 13 neglected to obtain clearance for research that clearly required ethical approval and 6 undertook investigations for which ethical approval was 
unnecessary (Fig. 2). Non-compliant and unconfirmed ethical clearance declined dramatically from 59\% pre-2011 to $19 \%$ for 2011 - 2014, with a further reduction to $17 \%$ for 2015 - 2018.

\section{Number of pages}

There was a wide range of page numbers (12 - 260), with a mean of 75.6 and median of 67. A 4-page difference in mean page numbers occurred between publication-ready and monograph mini-dissertations (Table 2).

\section{References}

The number of references listed ranged from 6 to 229, with a mean of 51 and a median of 40 (Table 2).

\section{MMed study sample/participant size}

Sample sizes ranged from 1, an unusual case study and comprehensive review, ${ }^{[23]}$ to an extensive sample of 28563 records. ${ }^{[24]}$ Thirteen MMeds lacked study sample numbers. Sample size figures gave little indication of the records sifted to achieve the final selection. For instance, Mopeli ${ }^{[25]}$ retrieved 883 files to obtain the 131 cases investigated. Reporting of such informative detail was seldom encountered (Table 2).

\section{Discussion}

The novelty of this study is that it presents, for the first time, a basic, tangible description of MMeds that have successfully fulfilled National Qualifications Framework (NQF) 9 requirements for a professional Master's by coursework and mini-dissertation. As such, it provides useful guidelines for registrars, supervisors and thought-leaders as to the size and scope of the degree, although it cannot indicate the quality of the MMed sampled. The literature was explored to contextualise and gain further understanding of the results of this study, thereby positioning the SA MMed in the global trainee specialist arena.

Zambian MMed programmes report a preponderance of observational studies (94\%). ${ }^{[26]}$ Elsewhere, $59.8 \%$ of general medicine ${ }^{[32]}$ and $76.9 \%$ of family medicine ${ }^{[33]}$ studies were reported as descriptive compared with the current $60 \%$ of SA MMed qualitative, mixed methods and descriptive quantitative studies. Nour-Eldien et al ${ }^{[28]}$ comment favourably on descriptive studies, deeming them to be inexpensive and useful to generate hypotheses for further studies of more rigorous designs. SA MMeds were almost equally prospective/retrospective in nature, which resonates with similar numbers for prospective studies in ophthalmology $(57 \%)^{[29]}$ and urology $(47.5 \%)^{[30]}$ dissertations. Prospective studies are considered to have higher scientific value than retrospective studies. ${ }^{[30]}$ The latter formed $50 \%$ and $76 \%$ of paediatric ${ }^{[31]}$ and radiology ${ }^{[32]}$ dissertations, respectively. In the case of radiology, this is considerably higher than the current $48 \%$ finding in the current study.

The wide range of research fields and approaches encountered is probably due to the 24 Colleges represented in the sample. Ranking, using levels of evidence, has been a logical way to contrast these diverse research approaches. Koca et al., ${ }^{[33]}$ employing a similar 'Evidence and grades of recommendation' grouping, found that $75 \%$ of orthopaedic theses were case control, case series and retrospective comparative studies, somewhat greater than the $60.9 \%$ for equivalent rankings for SA MMeds. Ideally, registrar research should be undertaken at the 'best' level of an evidence-based study approach. 'High level' studies, which comprised 5\% of the current sample, are equal to the $5 \%$ reported for 'high quality' studies (i.e. randomised

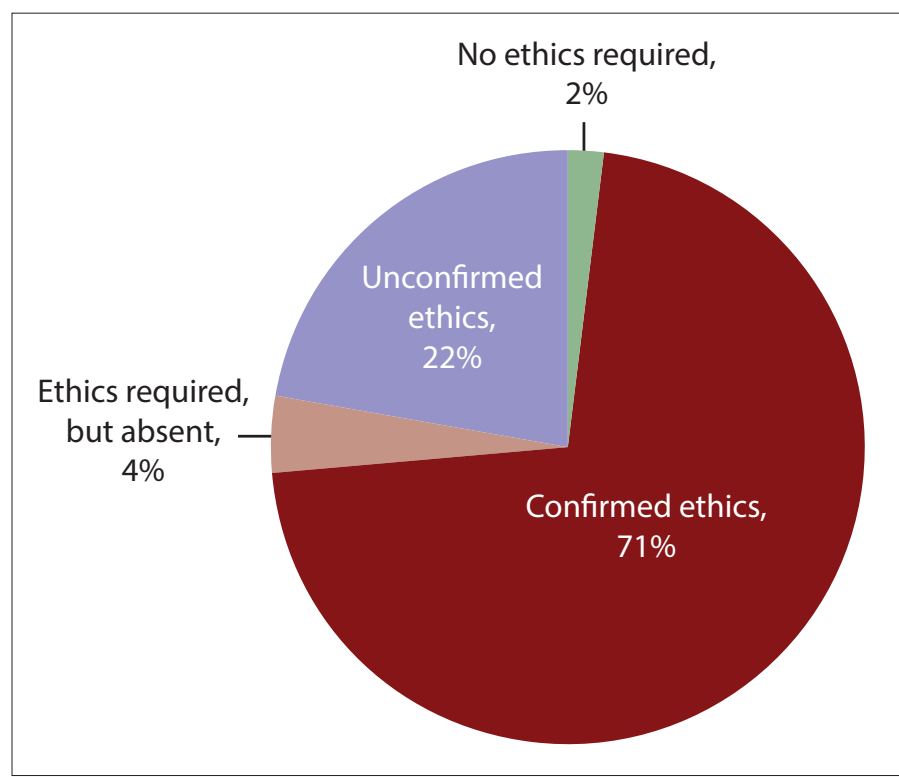

Fig. 2. Pie chart of ethical compliance of the 307 MMed mini-dissertations.

controlled trials) in family medicine theses. ${ }^{[28]}$ Elsewhere, $13 \%$ of paediatric residency research theses ${ }^{[31]}$ are reported as being randomised controlled trials, well above the SA MMed finding. According to Jaruratanasirikul and Khotchasing, ${ }^{[31]}$ forcing trainee specialists to undertake high-level studies is not realistic. These authors further state that high-level studies can be completed by registrars within the specified time constraints, provided that the studies are kept simple, with a small sample size and tailored for the limited amount of resident time that can be devoted to research. Prospective studies with 'higher scientific value' are further hampered by ethical and financial considerations. ${ }^{[32]}$

The complexity of ethical approval procedures (whether in terms of time or paperwork) is a major research constraint in resident research. ${ }^{[30,34]}$ This has led Sansone et al. ${ }^{[35]}$ to opt for Institutional Review Board (IRB)exempted research activities in an internal medicine residency training programme, rather than conducting research that requires expedited or full review. The SA MMed has not followed this course, with $<2 \%$ of studies requiring no ethical clearance. Ethical compliance has also steadily increased over the years in accordance with the National Health Act. ${ }^{[36]}$

With regard to data analysis, $93 \%$ of public health theses were quantitative studies ${ }^{[37]}$ compared with $82.7 \%$ of dissertations in the current study. The $38.8 \%$ of quantitative Finnish medical diploma theses using statistics to analyse data, ${ }^{[38]}$ approximate the current finding of $48 \%$. Two studies ${ }^{[31,34]}$ enlarge on the difficulties of doing statistically based research in resident research programmes due to lack of expertise and suboptimal information technology infrastructure in hospitals and teaching premises, a situation bedevilling SA MMed training.

Looming large in the registrar mind when embarking on the research project, are three questions: How many pages must I write? How many references must I have? How large should my study sample be? Therefore, data on the number of pages, references and research subjects were collected to provide some perspective on size, however inappropriate this may be. Fortunately, it seems that such questions are commonly encountered and the literature is able to provide comparative data. Page numbers for the $307 \mathrm{SA}$ 
MMeds are well aligned with those suggested - just $>60$ double-spaced pages for a coursework minor thesis ${ }^{[39]}$ and 40 - 60 double-spaced pages for a mini-dissertation/research report. ${ }^{[40]}$ Despite this consensus, page numbers in the current sample varied enormously owing to omissions and inclusions of items, as described in the results section. Even in this light, the 12-page monograph encountered in this study appears rather skimpy.

The number of references in the 307 mini-dissertations is also within the ranges suggested - $40-100$ for a minor coursework Master's ${ }^{\text {'39] }}$ and $28-215$ for a Master's in the health sciences. ${ }^{[40]}$ Mouton $^{[40]}$ is at pains to point out that the number of references depends on the kind of study undertaken and the field or discipline involved, which could go some way to explaining the range of references $(n=6-229)$ encountered in this study.

The diversity of studies, research questions and approaches encountered during this investigation makes it inappropriate to suggest a suitable sample or participant size. A power analysis for size and corresponding statistical significance can be calculated, but this does not assist in descriptive studies, when a limited sample is available or when time limitations restrict data gathering. Sansone et al. ${ }^{[35]}$ suggested a participant range of $300-400$ for legitimate statistical analysis in prospective studies, but warns of logistical problems such as IRB approval, data collection and data-entering efficiencies that could disrupt timeframes. Thomas ${ }^{[39]}$ goes further and makes some suggestions on sample size and research scope suitable for health science dissertations and theses. His section on a coursework Master's degree is worth quoting in full: 'It is usual [to] have one empirical study only or perhaps use secondary sources such as documents and/or previously collected data. For example, the study might be a clinical survey of a small group of patients or perhaps a social survey of a larger group of patients. Mind you, the results need to be statistically meaningful so there does need to be a decent sample size to avoid adverse examiner comment. In a social survey using an easily administered questionnaire the expectation might be for over 100 participants in the research, depending on the specific power requirements of the analysis to be performed. In a clinical study, perhaps a two-group intervention study with, say, a minimum of a dozen or so participants per group would be a basic expectation. However, if the measures taken contain a lot of error then the power of the design is likely to be inadequate.' He qualifies with the words, 'I have based my estimates on quite a few years of close observation of what seems to be acceptable to other thesis examiners'.

Publication-ready MMeds are a relatively new form of submission and an in-depth investigation into this format can be found elsewhere. ${ }^{[41]}$ Therefore, for completeness, only a few comments on this MMed format are given here. The data show that publication-ready mini-dissertation formats are becoming increasingly popular as a research output. This format is favoured by SA faculties of health science to meet university demands for subsidy-generating publications, while at the same time meeting academic obligations of the registrar research component. ${ }^{[42]}$ Additionally, time to completion for publication-ready mini-dissertations is significantly faster than for monograph-type dissertations. ${ }^{[43]}$

\section{Study limitations}

MMed mini-dissertations that are unavailable because of university uploading policy or because of delayed uploading could cause a lack of required randomness in the current sample, but it is felt that this has not materially detracted from the study findings. Two studies ${ }^{[32,33]}$ have similarly remarked on university libraries that fail to appropriately upload defended theses onto required databases, potentially affecting sampling strategies.
The thrust of available literature on MMed-type dissertations is predominantly on dissertation properties linked to publication, not content analysis per se. A further problem relates to the discipline-specific nature of the published studies that favour research methods best suited to the clinical discipline in question. Finally, it is not always clear how data categories have been organised in other publications, e.g. blurring of what is included in 'study design' and whether these categories are comparable with those in the current study.

\section{Conclusion}

In summary, there is agreement that the research vacuum in specialty training worldwide has been to the detriment of the profession as a whole and that research skills and evidence-based critique are required to enhance patient care and disciplinary professional status. This long-overdue article has provided basic content data on the SA MMed mini-dissertation, confirming the acquisition of a learned research skill as outlined by $\mathrm{R}$ Hift and C Aldous (Standardisation of the research component of the Master of Medicine (MMed) degree. Final recommendations. South African Committee of Medical Deans, 2017 - unpublished). Comparisons with the international literature indicate that the scope of the SA MMed, measured by the study variables, is roughly on a par with those provided by other global institutions. This study can serve to assist thought leaders in SA on how best to utilise a research component during registrar training, while at the same time honouring specialist practice and enhancing clinical and academic education.

\section{Declaration. None.}

Acknowledgements. Emeritus Prof. P E Cleaton-Jones is thanked for constructive criticism of the manuscript.

Author contributions. Sole author.

Funding. None.

Conflicts of interest. None.

1. Patel N, Naidoo P, Smith M, Loveland J, Govender T, Klopper J. South African surgical registrar perceptions of the research project component of training: Hope for the future? S Afr Med J 2016;106(2):169-171. https://doi org/10.7196/samj.2016v106i2.10310

2. Szabo CP, Ramlall S. Research competency and specialist registration: Quo vadis? S Afr Med J 2016;106(12):1183-1185. https://doi.org/10.7196/samj.2016.v106i12.11217

3. Biccard BM, Dyer RA, Swanevelder JL, Coetzee JF, Shafer SL. Is the HPCSA requirement for a research minidissertation for specialist registration the best option? S Afr J Anaesth Analg 2017;23(4):4-6.

4. Rodseth RN, Wise R, Bishop D. Polluting the well. S Afr J Anaesth Analg 2017;23(6):5.

5. Thomson SR. How to implement 'the research component' of the MMed degree? Transactions 2009;53(2):52-53.

6. Ahmad S, de Oliveira GS, McCarthy RJ. Status of anesthesiology resident research eduction in the United States: Structured education programs increase resident research productivity. Anesth Analg 2013;116(1):205-210. https:// Structured education programs increase resion
doi.org/10.1213/ANE.0b013e31826fo87d

7. Kersnik J, Ungan M, Klemenc-Ketis Z. Why does teaching research skills to family medicine trainees make sense? Kersnik J, Ungan M, Klemenc-Ketis Z. Why does teaching research skills to family
Eur J Gen Pract 2015;21(4):253-256. https://doi.org/0.3109/13814788.2015.1057813

8. Himelhoch S, Edwards S, Ehrenreich M, Luber MP. Teaching lifelong research skills in residency: Implementation and outcome of a systematic review and meta-analysis course. J Grad Med Educ 2015;7(3):445-450. https://doi. org/10.4300/JGME-D-14-00505.1

9. Abramson EL, Naifeh MM, Stevenson MD, et al. National training among pediatric residency programs - a nationa assessment. Acad Med 2014;89(12):1674-1680. https://doi.org/10.1097/ACM.0000000000000404

10. Bourgeois JA, Hategan A, Azzam A. Competency-based medical education and scholarship: Creating an active academic culture during residency. Perspect Med Educ 2015;4(5):254-258. https://doi.org/10.1007/s40037-015-0218-4 1. Cheung G, Gale C, Menkes DB. What affects completion of the scholarly project? A survey of RANZCP trainees Australas Psychiatry 2018;26(5):1-6. https://doi.org/10.1177/1039856218772250

12. Elobu AE, Kintu A, Galukande M, et al. Research in surgery and anesthesia: Challenges for post-graduate trainees in Uganda. Educ Health 2015;28(1):11-15. https://doi.org/10.4103/1357-6283.161826

13. Pathak R, Chaudhary C, Mishra P, Sanfwan G, Thakre M. Perception, practices and barriers towards health research Pathak R, Chaudhary C, Mishra P, Sanfwan G, Thakre M. Perception, practices and barriers towards health research
among young medical professionals of northern India. Int J Health Sci Res 2015;5(2):11-19. http://www.ijhsr.org/ among young medical professionals of northern India. Int J Heald
IJHSR_Vol.5_Issue.2_Feb2015/2.pdf (accessed 28 February 2019).

14. Rivera JA, Levine RB, Wright SM. Completing a scholarly project during residency training. Perspectives of residents who have been successful. J Gen Intern Med 2005;20(4):366-369. https://doi.org/10.1111/j.1525-1497.2005.04157.x 15. Wang A, Retrouvey H, Hawker G. Medical trainees under too much pressure to do research. Opinion, 21 June 2017 http://healthydebate.ca/opinions/medical-trainees-research (accessed 9 February 2019).

16. Aldous $\mathrm{CM}$, Adhikari A, Rout CC. The research component of specialist registration - a question of alligators and swamps? A personal view. S Afr Med J 2015;105(1):21-22. https://doi.org/10.7196/samj.8732

17. Cluver CA. Maternal position during caesarean section for preventing maternal and neonatal complications: A Cochrane Review. MMed dissertation. Cape Town: Stellenbosch University, 2011. http://scholar.sun.ac.za/ handle/10019.1/17831 (accessed 14 September 2018) 
18. Umeh AE, Nkombua L. A study of the knowledge and practice of lifestyle modification in patients with type 2 diabetes mellitus in Middelburg sub-district of Mpumalanga. S Afr Fam Pract 2018:60(1):26-30. https://doi.or $10.1080 / 20786190.2017 .1364012$

19. Pienaar JP. Opname van opinie van regslui ten opsigte van doeltreffendheid van geregtelike post mortem in die Wes-Kaap. MMed dissertation. Cape Town: Stellenbosch University, 2001. http://scholar.sun.ac.za/ handle/10019.1/52386 (accessed 3 May 2018).

20. Alagbe AO. Quality improvement cycle in Opuwo District Hospital HIV/AIDS Clinic, Kunene Region, Namibia. MMed dissertation. Cape Town: Stellenbosch University, 2013. http://scholar.sun.ac.za/handle/10019.1/9721 (accessed 8 March 2018)

21. Taylor JJ. Appeals against assisted and involuntary admission under the Mental Health Care Act No. 17 of 2002 in Region A, Gauteng Province, South Africa, between December 2004 and December 2011. MMed dissertation. Johannesburg: University of the Witwatersrand, 2015. http://wiredspace.wits.ac.za/handle/10539/1847 (accessed 30 March 2018),

22. Ferreira G. Assessment of the impact of family physicians in the district health system of the Western Cape South Africa. MMed dissertation. Cape Town: Stellenbosch University, 2015. http://scholar.sun.ac.za/ handle/10019.1/99325 (accessed 8 March 2018)

23. Bhatta AD. The orthopaedic manifestations of osteogenesis imperfecta: A collective review. MMed dissertation. Durban: University of KwaZulu-Natal, 2016. http.//researchspace ukzn.ac.za/handle/10413/14794 (accessed 7 March 2018).

24. Douglas-Jones P. Tonsillectomy rates in the South African private healthcare sector. MMed dissertation. Cape Town: University of Cape Town, 2016. https://open.uct.ac.za/handle/11427/27824 (accessed 1 June 2018),

25. Mopeli RK. An audit of primary medical conditions in children admitted to the pediatric intensive care unit of the Charlotte Maxeke Johannesburg Academic Hospital. MMed dissertation. Johannesburg: University of the the Charlotte Maxeke Johannesburg Academic Hospital. MMed dissertation. Johannesburg: U
Witwatersrand, 2017. http://wiredspace.wits.ac.za/handle/10539/23297 (accessed 7 March 2018).

26. Ahmed Y, Kanyengo CW, Akakandelwa A. Mapping postgraduate research at the University of Zambia: A review of dissertations for the Master of Medicine programme. Med J Zambia 2010;37(2):52-57.

27. Balaghafari A, Siamian H, Kharamin F, Rashida SS, Ghahrani N. Quantitative assessment of theses Mazandaran University of Medical Sciences years - (1995-2014). Acta Inform Med 2016;24(4):281-285. https:/ oi.org/10.5455/aim 2016.24.281-285

28. Nour-Eldien H, Mansour NM, Abdulmajeed AA. Master's and doctoral theses in family medicine and their publication output, Suez Canal University, Egypt. J Fam Med Prim Care 2015;4(2):162-167. https://do org/10.4103/2249-4863.154622

29. Bayramlar H, Karadag R, Gurturk AYK, Ocal A, Dag Y, Sari U. Publication patterns of ophthalmology residency mini-dissertations in Turkey. Eur J Gen Med 2015;12(3):213-216. https://doi.org/10.15197/sabad.1.12.45

30. Yüksel M, İpekçi T, Tunçkıran A. Publication patterns and citation analysis of urology mini-dissertations written at medical faculties from Turkey between 2008 - 2011: A cross sectional study. Turk J Urol 2018;44(4):341-345. https://doi.org/10.5152/tud.2017.32042
31. Jaruratanasirikul S, Khotchasing W. Publication of pediatric residency research theses from Prince of Songk University, Hat Yai, Thailand. Asian Biomed 2015;9(2):231-235. https://doi.org/10.5372/1905-7415.0902.392 32. Chassagnon G, Dangouloff-Ros V, Vilgrain V, Ronot M. Academic productivity of French radiology residents Where do we stand? Diagn Interv Imaging 2016;97:211-218. https://doi.org/10.1016/j.diii.2015.08.001

33. Koca K, Ekinci S, Akpancar S, Gemci MH, Erşen Ö, Akyldız F. An analysis of orthopaedic theses in Turkey: Evidence levels and publication rates. Acta Orthop Traumatol Turcica 2016;50(5):562-566. https://doi. org/10.1016/j.aott.2016.03.001

34. Amgad M, Man Kin Tsui M, Liptrott SJ, Shash E. Medical student research: An integrated mixed-methods systematic review and meta-analysis. PLoS ONE 2015;10(6):e0127470. https://doi.org/10.1371/journal. pone. 0127470

35. Sansone RA, Wiederman MW, Sawyer RJ. Effective research strategies for trainees in internal medicine residency programmes. Prim Care Companion CNS Disord 2015;17(1):1-8. https://doi.org/10.4088/ PCC.14r01712

36. National Department of Health. Ethics in Health Research: Principles, Processes and Structures. 2nd ed. Pretoria: NDoH, 2015

37. Hollmann M, Borrell C, Garin O, Fernández E, Alonso J. Factors influencing publication of scientific articles derived from Masters theses in public health. Int J Public Health 2015;60(4):495-504. https://doi.org/10.1007/ s00038-015-0664-0

38. Niemenin P, Sipilä K, Takkinen H-A, Renko M, Risteli L. Medical theses as part of the scientific training in basic medical and dental education: Experiences from Finland. BMC Med Educ 2007;7(5):1-7. https://doi org/10.1186/1472-6920-7-51

39. Thomas SA. How to Write Health Science Papers, Mini-dissertations and Theses. Sydney: Churchil Livingstone, 2005:29.

40. Mouton J. How to Succeed in Your Masters and Doctoral Studies. Pretoria: Van Schaik, 2001.

41. Grossman ES. Publication rate of 309 MMed dissertations submitted between 1996 and 2017: Can registrar fulfil HPCSA Form 57 MED amendments? S Afr Med J 2020;110(4):302-307. https://doi.org/10.7196/ SAMJ.2020.v110i4.14339

42. Rout C, Aldous C, Hift R. Response to concerns expressed in the journal regarding the HPCSA requirement for registrar (MMed) research. S Afr J Anaesth Analg 2018;24(2):48- 50.

43. Grossman ES. How long does it take a registrar to complete the compulsory research project enabling specialist registration? S Afr Med J 2019;109(4):254-258. https://doi.org/10.7196/SAMJ.2019.v109i4.13377

Accepted 4 November 2019 